\title{
Changes in transfusion and fluid therapy practices in severely injured children: an analysis of 5118 children from the TraumaRegister DGU ${ }^{\circledR}$
}

\author{
Florian Piekarski ${ }^{1}$ [ $\cdot$ Jost Kaufmann ${ }^{2,3} \cdot$ Thomas Engelhardt $^{4}$. Florian J. Raimann ${ }^{1} \cdot$ Thomas Lustenberger $^{5}$. \\ Ingo Marzi ${ }^{5} \cdot$ Rolf Lefering $^{3,6} \cdot$ Kai Zacharowski $^{1} \cdot$ Patrick Meybohm ${ }^{7} \cdot$ TraumaRegister DGU $^{8}$
}

Received: 13 May 2020 / Accepted: 19 June 2020 / Published online: 29 June 2020

(c) The Author(s) 2020

\begin{abstract}
Purpose Trauma is the leading cause of death in children. In adults, blood transfusion and fluid resuscitation protocols changed resulting in a decrease of morbidity and mortality over the past 2 decades. Here, transfusion and fluid resuscitation practices were analysed in severe injured children in Germany.

Methods Severely injured children (maximum Abbreviated Injury Scale (AIS) $\geq 3$ ) admitted to a certified trauma-centre (TraumaZentrum DGU®) between 2002 and 2017 and registered at the TraumaRegister DGU® were included and assessed regarding blood transfusion rates and fluid therapy.

Results 5,118 children (aged 1-15 years) with a mean ISS 22 were analysed. Blood transfusion rates administered until ICU admission decreased from 18\% (2002-2005) to 7\% (2014-2017). Children who are transfused are increasingly seriously injured. ISS has increased for transfused children aged 1-15 years (2002-2005: mean 27.7-34.4 in 2014-2017). ISS in nontransfused children has decreased in children aged 1-15 years (2002-2005: mean 19.6 to mean 17.6 in 2014-2017). Mean prehospital fluid administration decreased from 980 to $549 \mathrm{ml}$ without affecting hemodynamic instability.

Conclusion Blood transfusion rates and amount of fluid resuscitation decreased in severe injured children over a 16-year period in Germany. Restrictive blood transfusion and fluid management has become common practice in severe injured children. A prehospital restrictive fluid management strategy in severely injured children is not associated with a worsened hemodynamic state, abnormal coagulation or base excess but leads to higher hemoglobin levels.
\end{abstract}

Keywords Paediatric trauma patients $\cdot$ Transfusion practice $\cdot$ Patient blood management $\cdot$ Outcome $\cdot$ Mortality $\cdot$ Fluid therapy $\cdot$ Volume therapy $\cdot$ Serious injured children · TraumaRegister DGU® (TR-DGU)

\section{Introduction}

Registration Registered under the TR-DGU project ID: 2019049.

Florian Piekarski

florian.piekarski@kgu.de

1 Department of Anaesthesiology, Intensive Care Medicine and Pain Therapy, University Hospital Frankfurt, Goethe University, Frankfurt, Germany

2 Department for Paediatric Anaesthesia, Children's Hospital Cologne, Cologne, Germany

3 Faculty of Health, University of Witten/Herdecke, Witten, Germany

4 Department for Anesthesia, Montreal Children's Hospital, Montreal, Canada
Trauma is the leading cause of death in children [1], with severe haemorrhage as the primary contributing factor [2-4]. Massive transfusion in children is known to be associated

5 Department of Trauma, Hand and Reconstructive Surgery, University Hospital Frankfurt, Goethe-University, Frankfurt, Germany

6 IFOM, Institute for Research in Operative Medicine, Faculty of Health, University Witten/Herdecke, Cologne, Germany

7 Department of Anaesthesia and Critical Care, University Hospital Würzburg, Würzburg, Germany

8 Committee On Emergency Medicine, Intensive Care and Trauma Management (Sektion NIS) of the German Trauma Society (DGU), Berlin, Germany 
with several risks resulting in significant morbidity and mortality (3). Treatment of those severely injured children is a challenge due to differences in physiology and anatomy. Fluid and transfusion management plays an important role in resuscitation of severe haemorrhage not only in children.

While blood transfusion rates in serious injured adults decreased over the last decade and were associated with a reduction in morbidity and mortality [5], there are no sufficient data that confirm a similar change in practice in children. Similarly, positive fluid balance has been associated with higher mortality rates in adult trauma patients (5), but no data for fluid management in paediatric trauma patients are available. We hypothesized, that similar to adults, seriously injured children also receive less blood transfusion and less fluids. This hypothesis was tested by an analysis of the TraumaRegister DGU® (TR-DGU).

\section{Materials and methods}

The TraumaRegister DGU® (TR-DGU) of the German Trauma Society (DGU) was established in 1993. The aim of this multi-centre database is a pseudonymised and standardised documentation of severely injured patients [6].

Data are collected prospectively for four consecutive time periods from the site of the accident until discharge from hospital: (a) pre-hospital phase, (b) emergency room and initial surgery, (c) intensive care unit and (d) hospital discharge. The documentation includes detailed information on patient demographics, injury pattern, comorbidities, preand in-hospital management, course on intensive care unit, relevant laboratory findings including data on transfusion and outcome of each individual. The inclusion criteria are admission to hospital via emergency room with subsequent intensive care unit (ICU) / intensive care medicine (ICM) care or admission to the hospital with vital signs and death before admission to ICU.

The infrastructure for documentation, data management, and data analysis is provided by the "AUC-Academy for Trauma Surgery", a company affiliated to the DGU. The scientific leadership is provided by the "Committee on Emergency Medicine, Intensive Care and Trauma Management (Sektion NIS)" of the DGU. The participating hospitals submit their data pseudonymised into a central database via a web-based application. Scientific data analysis is approved according to a peer review procedure, as provided by the publication's guideline of TR-DGU. The participating hospitals are primarily located in Germany (90\%) but a rising number of hospitals of other countries contribute data as well (at the moment from Austria, Belgium, China, Finland, Luxembourg, Slovenia, Switzerland, The Netherlands, and the United Arab Emirates). Currently, approximately 33,000 cases from more than 650 hospitals are registered into the database annually.

Participation in TR-DGU is voluntary. However, for hospitals associated with TraumaNetzwerk DGU®, the entry of at least a basic data set is mandatory as part of the quality management program.

The present study has been reviewed by the TR-DGU review board and is registered under the TR-DGU project id: 2019-049. The study was performed in accordance with the Declaration of Helsinki.

\section{Inclusion criteria}

Patients (aged 1-15 years) for primary analysis and young adults (16-25 years) as reference were included with an Abbreviated Injury Scale (AIS) of 3 or higher (serious injury) [7] who were directly admitted to a German trauma centre (TraumaZentrum DGU®) from 2002 to 2017. Early transfers out ( $<48 \mathrm{~h}$ after admission) were excluded due to missing final outcome. Children younger than 1 year of age were excluded due to limited sample sizes (median $n=11$ / year). Paediatric patient groups were defined by $1-15$ as well as subgroups of 1-5, 6-10 and 11-15 years of age (Fig. 1).

\section{Statistical analysis}

Statistical analysis was performed using IBM® SPSS $®$ Statistics (Version 24, IBM®, Armonk, New York). Univariable and multivariable analysis were performed. Descriptive results are presented as count/ percentages, median or mean \pm standard deviation (SD). Multivariable analysis based on a logistic regression model was performed for risk of death analysis: RISC II score was combined with blood transfusion [8]. A $p$ value of $<0.05$ was considered statistically significant.

Injury Severity Score (ISS), systolic blood pressure on scene, haemoglobin-concentration and base excess were compared. Mortality between patients received transfusion and those who did not has been analysed.

\section{Results}

A total of 27,595 serious injured patients aged 1-25 including 5118 children (aged 1-15 years) were identified between 2002 to 2017 (Fig. 1). While the median ISS of young adult (16-25 years) and older children (11-15 years) dropped over the years (2002-2017) from 22 to 18 and from 19 to 17, the ISS for children 1-10 (median 16) did not change significantly. A decrease of the ISS is also shown in the subgroup analysis by age and years (Table 1). More boys were seriously injured than girls (Table 2). In children older than 5 years of age and young adults, road traffic collisions were 
Fig. 1 Flow sheet patient inclusion. Patients (aged 1-15 years) for primary analysis and young adults (16-25 years) as reference were included with an Abbreviated Injury Scale (AIS) of 3 or higher who were directly admitted to a German trauma centre (TraumaZentrum DGUß) from 2002 to 2017

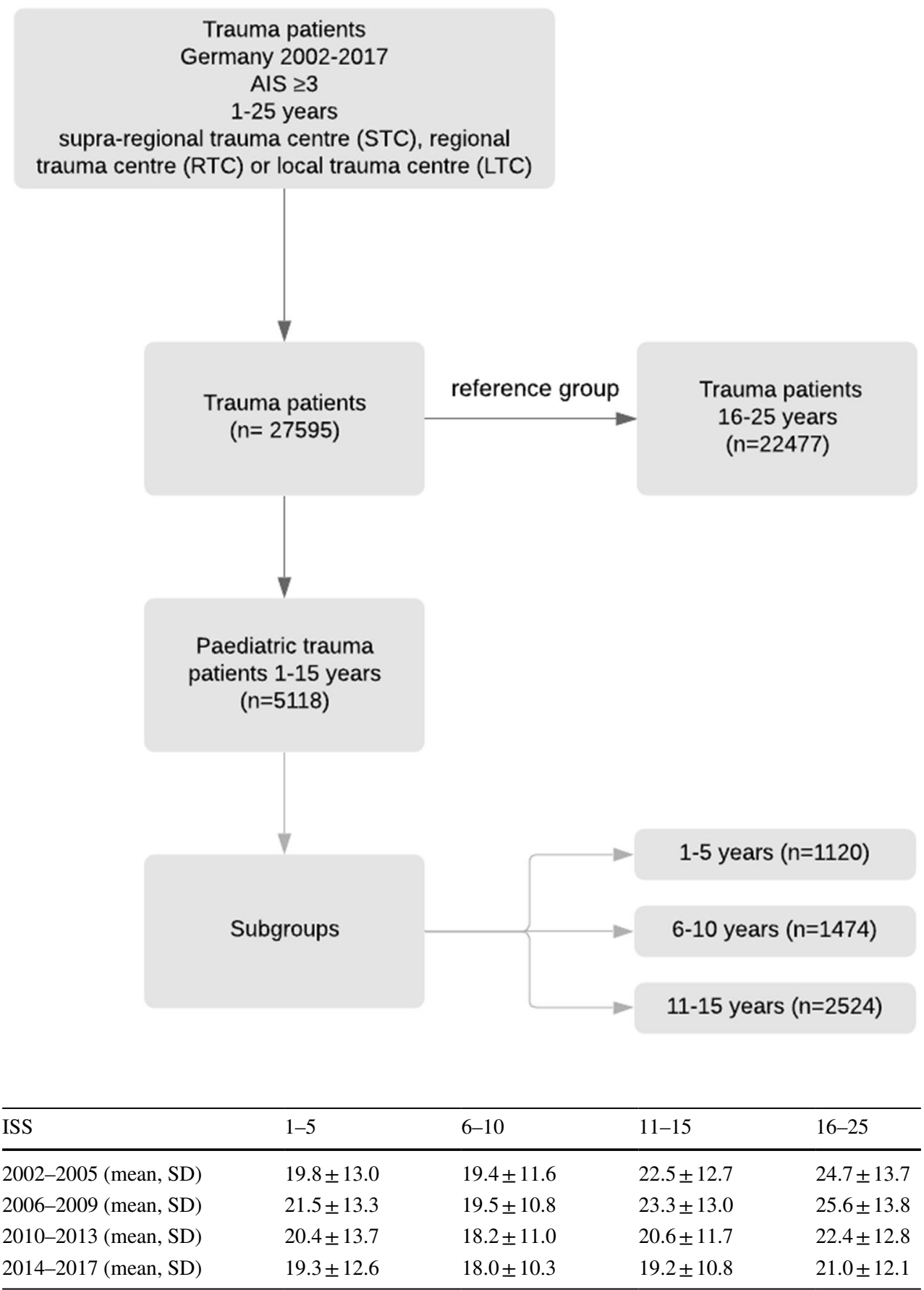

\begin{tabular}{lllll}
\hline ISS & $1-5$ & $6-10$ & $11-15$ & $16-25$ \\
\hline 2002-2005 (mean, SD) & $19.8 \pm 13.0$ & $19.4 \pm 11.6$ & $22.5 \pm 12.7$ & $24.7 \pm 13.7$ \\
2006-2009 (mean, SD) & $21.5 \pm 13.3$ & $19.5 \pm 10.8$ & $23.3 \pm 13.0$ & $25.6 \pm 13.8$ \\
2010-2013 (mean, SD) & $20.4 \pm 13.7$ & $18.2 \pm 11.0$ & $20.6 \pm 11.7$ & $22.4 \pm 12.8$ \\
2014-2017 (mean, SD) & $19.3 \pm 12.6$ & $18.0 \pm 10.3$ & $19.2 \pm 10.8$ & $21.0 \pm 12.1$ \\
\hline
\end{tabular}

Table 1 Development of the Injury Severity Score by years and age groups the leading cause for hospital admission. Leading injury in children aged $1-5$ years is severe brain injury (Table 2 ).

\section{Blood transfusion}

Blood transfusion rates (administered until ICU admission) decreased from $17.6 \%$ during the observation period of 2002-2005 to $7.0 \%$ in 2014-2017. Subgroup analysis showed a decrease in all age sub-groups: Blood transfusion decreased from $7.8 \%$ (2002-2005) to 5.9\% (2014-2017;
6-10 years) and from $25.9 \%$ to $8.0 \%$ (1-5 years) (Fig. 2). In young adults (16-25 years) transfusion rates decreased also from $30.0 \%$ for the period of $2002-2005$ to $10.3 \%$ in 2014-2017. In-hospital mortality rate for transfused children (1-15) increased from $21.7 \%$ (2002-2005) to $41.9 \%$ (2014-2017).

Multivariable risk of death analysis (RISC II Score + transfusion) showed a higher in-hospital mortality in transfused children than in not transfused children $(\mathrm{OR}=1.61,95 \%$ Confidence interval 1.10-2.35). Mortality 
Table 2 Patient characteristics

\begin{tabular}{lllll}
\hline Age & $1-5(n=1120)$ & $6-10(n=1474)$ & $11-15(n=2524)$ & $16-25(n=22,477)$ \\
\hline Sex male $(\%, n)$ & $62.5 \%(698)$ & $64.8 \%(954)$ & $63.3 \%(1595)$ & $75.1 \%(16,836)$ \\
Sex female $(\%, n)$ & $37.5 \%(419)$ & $35.2 \%(519)$ & $36.7 \%(926)$ & $24.9 \%(5585)$ \\
Mean ISS (SD) & $20.0(13.1)$ & $18.4(10.7)$ & $20.6(11.7)$ & $22.5(12.9)$ \\
Transfusion until ICU admission $(\%, n)$ & $11.4 \%(128)$ & $6.1 \%(90)$ & $10.0 \%(252)$ & $15.1 \%(3388)$ \\
Additional FFP, if transfused $(\%, n)$ & $59.4 \%(41)$ & $62.5 \%(60)$ & $50.0 \%(75)$ & $45.2 \%(70)$ \\
Traffic accident $(\%, n)$ & $39.5 \%(429)$ & $64.2 \%(927)$ & $66.7 \%(1657)$ & $75.6 \%(16,722)$ \\
Transport by rescue helicopter $(\%, n)$ & $35.6 \%(377)$ & $35.5 \%(508)$ & $31.6 \%(762)$ & $29.9 \%(6481)$ \\
Intubation $(\%, n)$ & $38.4 \%(411)$ & $35.7 \%(511)$ & $38.3 \%(942)$ & $41.0 \%(9084)$ \\
Severe brain injury $(\%, n)$ & $62.2 \%(697)$ & $52.9 \%(780)$ & $47.2 \%(1192)$ & $39.1 \%(8778)$ \\
\hline
\end{tabular}

ISS Injury Severity Score; $p R B C$ packed red blood cells

Fig. 2 Development of transfusion rates. Development of transfusion rates in serious injured children and young adults 2002-2017

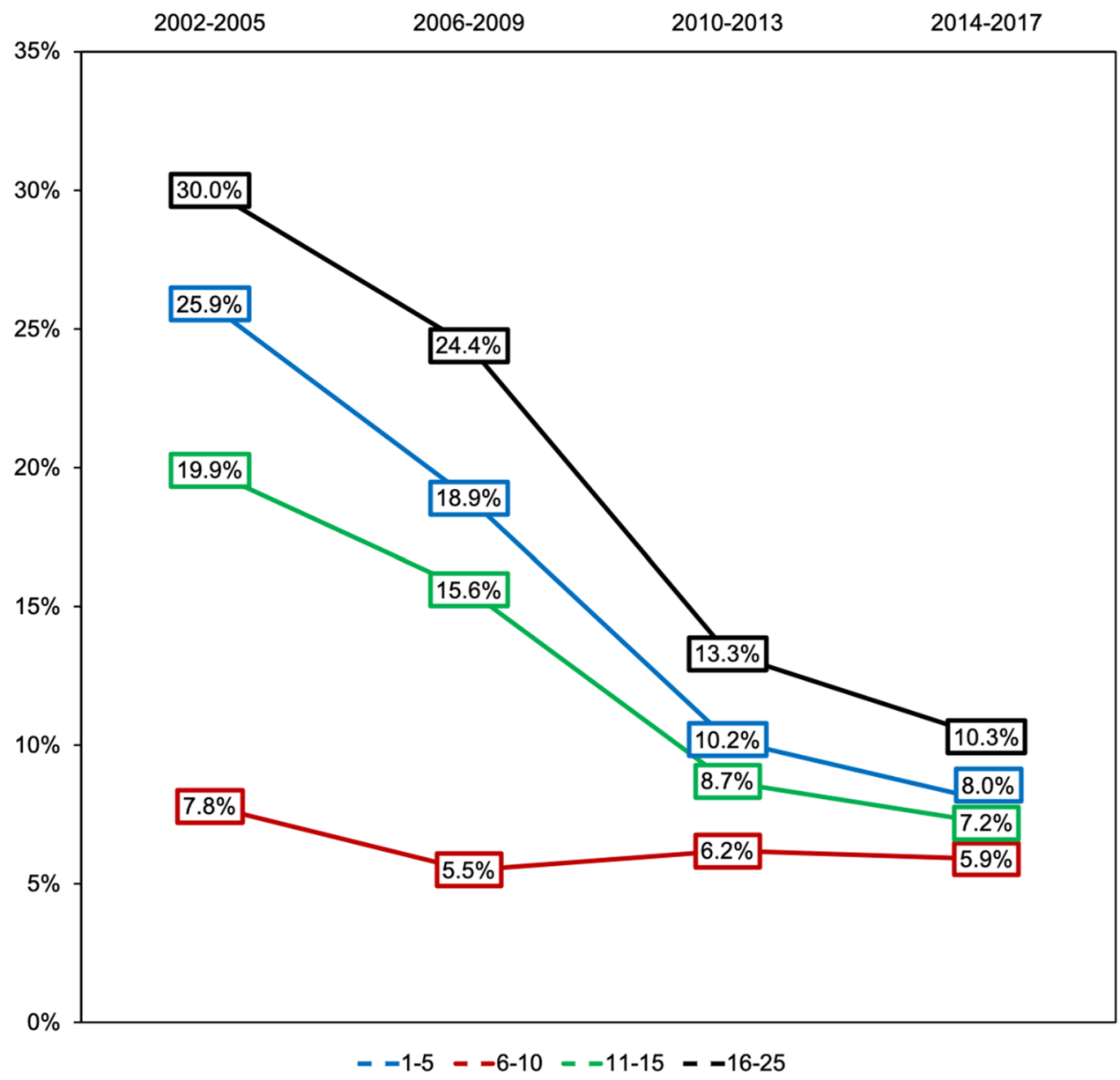

rates in transfused children were higher than predicted by RISC II scores (Table 3). ISS has risen in transfused children aged 1-15 years (2002-2005: mean 27.7 to mean 34.4 in 2014-2017). The ISS for non-transfused children fell in children aged $1-15$ years (2002-2005: mean 19.6 to mean 17.6 in 2014-2017) (Table 3).

\section{Fluid resuscitation, coagulation and blood pressure}

The amount of administered prehospital intravenous fluid decreased in all age groups (Fig. 3). While 1-15-yearold children received in mean $980 \mathrm{ml}$ of fluids in the years 2002-2005, only $549 \mathrm{ml}$ (mean) were administered 
Table 3 Mortality rates with and without blood transfusion in 1-15-year-old children

\begin{tabular}{llllllll}
\hline Year & $n$ & $\begin{array}{l}\text { Mortality } \\
\text { overall (\%) }\end{array}$ & $\begin{array}{l}\text { Mortality if not } \\
\text { transfused (\%) }\end{array}$ & $\begin{array}{l}\text { Mortality if } \\
\text { transfused (\%) }\end{array}$ & $\begin{array}{l}\text { ISS if not trans- } \\
\text { fused (Mean, SD) }\end{array}$ & $\begin{array}{l}\text { ISS if transfused } \\
(\text { Mean, SD) }\end{array}$ & $\begin{array}{l}\text { RISC II prognosis } \\
\text { if transfused (\%) }\end{array}$ \\
\hline 2002-2005 & 393 & 9.7 & 7.1 & 21.7 & $19.6(12.0)$ & $27.7(12.9)$ & 19.4 \\
$2006-2009$ & 702 & 8.1 & 5.0 & 28.1 & $20.0(10.8)$ & $34.4(15.6)$ & 29.5 \\
$2010-2013$ & 1811 & 7.7 & 5.2 & 36.0 & $18.4(10.2)$ & $36.3(16.9)$ & 36.5 \\
$2014-2017$ & 2212 & 6.6 & 3.9 & 41.9 & $17.7(9.6)$ & $34.4(16.3)$ & 36.7 \\
\hline
\end{tabular}

$p R B C$ packed red blood cells

Fig. 3 Development of prehospital fluid therapy. Development of mean prehospital fluid therapy $(\mathrm{ml})$ in serious injured children and young adults 2002-2017

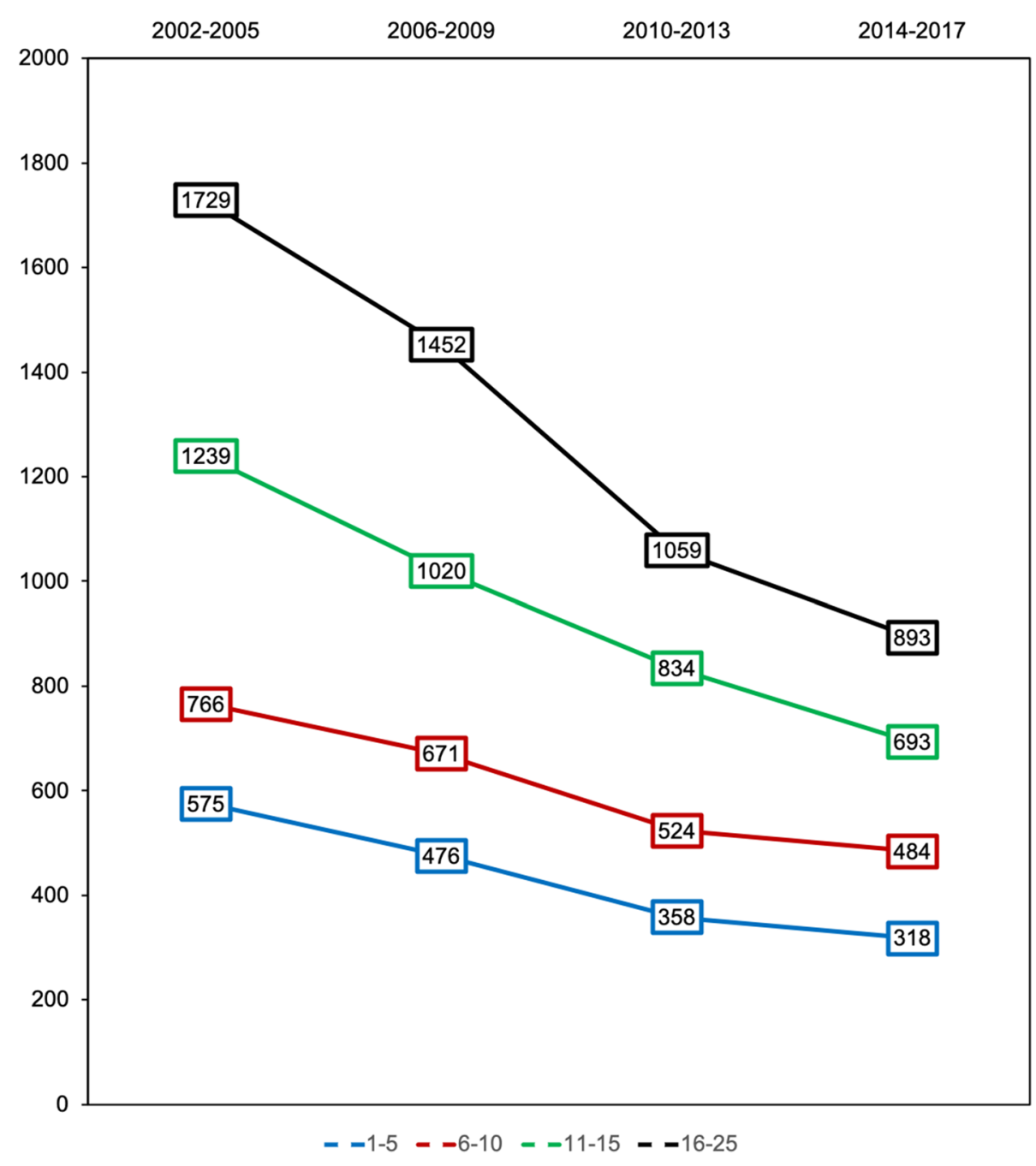

between 2014-2017. Fluid resuscitation in the Emergency Room (ER) decreased from mean $1685 \mathrm{ml}$ to mean $765 \mathrm{ml}$ (Tables 4 and 5) during the respective periods. First Base Excess measured in ER increased from mean -3.41 to $2.34 \mathrm{mmol} / \mathrm{l}$ between the 2 observed periods. Mean
Hemoglobin Concentration 10.96 and $12.0 \mathrm{~g} / \mathrm{dl}$, respectively, and mean International Normalized Ratio (INR) 1.31 and 1.2 , respectively, were not significantly affected. Documented prehospital and first ER systolic blood pressure increased over the years (Table 5). 
Table 4 Fluid therapy, coagulation and blood pressure in ER 1-15 years

\begin{tabular}{|c|c|c|c|c|c|c|c|}
\hline Years & $\begin{array}{l}\text { RR Syst. PH } \\
\mathrm{mmHG}\end{array}$ & $\begin{array}{l}\text { RR Syt. ER } \\
\text { mmHG }\end{array}$ & $\begin{array}{l}\text { Hb Level ER } \\
\text { g/dl }\end{array}$ & INR ER & $\begin{array}{l}\mathrm{BE} \\
\mathrm{ER} \\
\mathrm{mmol} / \mathrm{l}\end{array}$ & $\begin{array}{l}\text { Fluids } \\
\mathrm{PH} \\
\mathrm{ml}\end{array}$ & $\begin{array}{l}\text { Fluids } \\
\text { ER } \\
\mathrm{ml}\end{array}$ \\
\hline 2002-2005 (mean, SD) & $106(25)$ & $113(22)$ & $11.0(2.2)$ & $1.31(0.47)$ & $-3.4(4.6)$ & $980(779)$ & $1685(1656)$ \\
\hline 2006-2009 (mean, SD) & $109(24)$ & $116(24)$ & $11.3(2.2)$ & $1.30(0.68)$ & $-3.1(5.5)$ & $829(663)$ & $1313(1260)$ \\
\hline 2010-2013 (mean, SD) & $109(28)$ & $112(26)$ & $11.9(2.1)$ & $1.22(0.46)$ & $-2.8(5.0)$ & $649(554)$ & $745(852)$ \\
\hline 2014-2017 (mean, SD) & $114(28)$ & $116(25)$ & $12.0(2.0)$ & $1.20(0.53)$ & $-2.3(4.8)$ & $549(450)$ & $766(982)$ \\
\hline
\end{tabular}

$P H$ prehospital; ER emergency room; INR International Normalized Ratio; $B E$ base excess

Table 5 INR, BE, RR systolic in ER

\begin{tabular}{lllll}
\hline INR & $1-5$ & $6-10$ & $11-15$ & $16-25$ \\
\hline 2002-2005 (mean, SD) & $1.30 \pm 0.39$ & $1.30 \pm 0.38$ & $1.32 \pm 0.54$ & $1.37 \pm 084$ \\
2006-2009 (mean, SD) & $1.38 \pm 0.87$ & $1.21 \pm 0.49$ & $1.32 \pm 0.67$ & $1.35 \pm 0.82$ \\
2010-2013 (mean, SD) & $1.29 \pm 0.72$ & $1.22 \pm 0.47$ & $1.20 \pm 0.30$ & $1.24 \pm 0.64$ \\
2014-2017 (mean, SD) & $1.28 \pm 0.75$ & $1.20 \pm 0.55$ & $1.19 \pm 0.39$ & $1.19 \pm 0.55$ \\
\hline BE & $1-5$ & $6-10$ & $11-15$ & $16-25$ \\
\hline 2002-2005 (mean, SD) & $-4.1 \pm 4.7$ & $-3.2 \pm 3.6$ & $-3.3 \pm 5.1$ & $-3.5 \pm 4.7$ \\
2006-2009 (mean, SD) & $-5.0 \pm 6.0$ & $-3.8 \pm 3.8$ & $-2.2 \pm 5.9$ & $-3.3 \pm 4.7$ \\
2010-2013 (mean, SD) & $-4.4 \pm 5.9$ & $-2.8 \pm 5.2$ & $-2.1 \pm 4.4$ & $-2.6 \pm 4.8$ \\
2014-2017 (mean, SD) & $-3.8 \pm 5.7$ & $-2.1 \pm 4.4$ & $-1.8 \pm 4.4$ & $-2.0 \pm 4.7$ \\
\hline RR Sys. prehospital & $1-5$ & $6-10$ & $11-15$ & $16-25$ \\
\hline 2002-2005 (mean, SD) & $106 \pm 20$ & $103 \pm 31$ & $108 \pm 26$ & $113 \pm 29$ \\
2006-2009 (mean, SD) & $101 \pm 21$ & $107 \pm 27$ & $113 \pm 26$ & $114 \pm 28$ \\
$2010-2013$ (mean, SD) & $100 \pm 31$ & $106 \pm 26$ & $114 \pm 27$ & $118 \pm 29$ \\
2014-2017 (mean, SD) & $102 \pm 34$ & $112 \pm 25$ & $119 \pm 26$ & $123 \pm 29$ \\
\hline
\end{tabular}

$I N R$ International Normalized Ratio; $B E$ base excess; $S D$ standard deviation

\section{Discussion}

Blood transfusion and fluid resuscitation practices changed over a 16-year period in Germany. Resuscitation and treatment of severely injured children is a significant challenge for all professionals involved. Children are a physiologically inhomogeneous group ranging from neonates to adolescents. Children who have suffered severe hemorrhage or have ongoing bleeding may require life-saving blood transfusion, however, an underestimation of blood loss is common [9].

We were able to demonstrate in our study that severely injured children receive fewer transfusions. The reasons for this cannot be directly deduced from the presented study. It remains to be assumed that more careful use of blood products, as it has been observed in the therapy of adults, has also been adopted in the care of children [5]. The reduction of fluid administration leads to a higher $\mathrm{Hb}$ level, which we were also able to show, and thus probably to fewer transfusion indications. At the same time, the coagulation system is less affected by fewer fluids being applied, which can lead to reduced blood loss.

Blood transfusions are recommended for hemoglobin $<5 \mathrm{~g} / \mathrm{dl}$ in non-life-threatening bleeding $[1,10]$. However, there is no evidence or clear guidance for children with haemoglobin between 5 and $7 \mathrm{~g} / \mathrm{dl}$. The European Society of Anaesthesiology recommends transfusion targets for bleeding children 7-9 g/dl [11]. In paediatric cardiac surgery, no differences in mortality, clinical outcome or complication between restrictive (hemoglobin $8.0 \mathrm{~g} / \mathrm{dl}$ ) and liberal group $(10.8 \mathrm{~g} / \mathrm{dl})$ have been found [12]. In subgroup of children with severe traumatic brain injury hemoglobin concentrations between $7-10 \mathrm{~g} / \mathrm{dl}$ are recommended [13]. There is little evidence regarding transfusion triggers, but rather expert opinions [9], as a recent review article also points out [14]. However, the validity of haemoglobin concentration should also be considered in bleeding children. Measured hemoglobin concentrations are only reliably associated with actual blood loss after adequate fluid replacement. Haemoglobin concentrations may approximately be normal within the first hour of therapy, if no adequate fluid resuscitation 
was provided. We recommend measuring $\mathrm{Hb}$, but with normal $\mathrm{Hb}$ levels and suspected relevant blood loss at the same time, the result should be critically reviewed to determine whether sufficient fluids have been substituted. However, an individual indication for blood transfusion should be considered and include setting, pre-existing disease, injury and parameters for insufficient oxygen delivery such as lactatic acidosis.

The use of massive transfusion protocols in pediatric trauma patients has not led to an improvement of in-hospital mortality or outcomes [15]. However, we still recommend preparation for challenging medical situations with supporting aids such as treatment protocols and dosage recommendations. It can be assumed that the recommendations are beneficial for faster and safer care [16]. In hemorrhagic shock a blood product ratio of 2:1:1 to 1:1:1 (RBCs, plasma, platelets) is recommended [10].

Although no data for the use of vasoactive drugs were available for analysis, it must be assumed that these were frequently used as lower rates of transfusion and infusion were described without a decline in systolic blood pressure measurements. One explanation for this may be that more expertise on the use of catecholamines has been developed in the therapy of children. The reason for this could be that pediatric emergency rulers or apps are now part of the standard equipment of emergency medical services and support the emergency physician in calculating the catecholamine dose [16]. Moreover, the use of pelvic slings and tourniquets, which are now widely available to reduce acute blood loss, leads to less blood loss and thus to higher blood pressure upon arrival in the emergency room. Patient Blood Management (PBM) addresses evidence-based transfusion medicine practice and is recommended by the World Health Organization (WHO) in order to avoid transfusion associated risks such as infections, anaphylaxis, transfusionassociated graft-versus-host diseases or immunomodulation [17]. Implementing principles to optimize erythropoiesis, minimizing blood loss and managing anaemia leading to minimization of allogenic blood transfusion are essences of this program [18, 19]. Giving attention to the point that incidence of adverse outcome in transfused pediatric patients is 1.3 times higher in children and 2.8 higher in neonates when compared with adults [20], implementing PBM programs in paediatric settings is a relevant and current topic [21-24]. Several strategies already implemented in adult PBM Programs can easily be implemented in paediatric care. In context of initial management of severe bleeding avoiding hypothermia, acidosis, low calcium concentration [19] and administration of tranexamic acid are recommended and should be part of an paediatric massive haemorrhage protocol. The implementation of localised PBM programs and recommendations on RBC transfusion thresholds may have led to a reduction of transfusion rates in paediatric trauma patients as shown.

The observed increase in mortality in transfused pediatric trauma patients is most likely due to selection bias, as these transfused children also show increased ISS over time. A similar trend of an increased mortality of transfused patients following a stricter transfusion policy was also described in adult trauma patients [5]. RISC II prognosis score makes its prognosis based on the findings at the time of admission to the emergency room. The fact that transfusions were subsequently required is an indication of a possible deterioration or complication (e.g., bleeding could not be stopped). This may further explain the difference in observed versus predicted mortality. It must also be considered that the participating hospitals in the registry have changed over the years. In the beginning, only level 1 hospitals (hospitals of maximum care) sent data, only from 2012/2013 it's safe to assume that all trauma in Germany are included in the analysis.

Reduction of prehospital admitted fluid resulted in higher hemoglobin concentrations in ER in this study. This is consistent with findings by Hussman et al. that demonstrate an association of increased volume replacement and higher blood transfusion rates, coagulopathy and increased mortality [25]. Aggressive fluid resuscitation is also known to be an independent risk factor after trauma [26] and is associated with fluid-related complications [27]. Comparable paediatric trauma data are available from Defence Trauma Registry of the US military for children suffering from blast injuries [28]. Normalization of INR, BE and systolic blood pressure under reduced fluid replacement have been observed in adults as well as in this current study [26].

Acute traumatic coagulopathy (ATC) is an early-onset syndrome and is common in adult and paediatric trauma patients [29, 30]. ATC is an independent predictor for mortality in children after severe trauma [31]. The TraumaRegister $\mathrm{DGU}^{\circledR}$ registers INR at admission to the ER as a standard parameter for coagulopathy. INR was reduced in the last quarter of our analysis, but coagulopathy as defined as an INR $>1.2$ is still common overall. Real time measurement of coagulation might be useful in treating severe injured children. Standard coagulation tests do not necessarily correlate with coagulopathies such as Shutdown Fibrinolysis and Acute Traumatic Coagulopathy (ATC). Viscoelastic haemostatic results are available only in a few cases of severe injured children in The TraumaRegister DGU®. Viscoelastic haemostatic assays (VHA) are currently not standard of care in bleeding paediatric trauma patients but may provide valuable data for goal-directed haemostatic therapy in these patients [32, 33]. Prospective studies investigating viscoelastic monitoring-based therapy in paediatric trauma patients are needed. 


\section{Limitations}

The data are taken from the TraumaRegister DGU®. Due to a possible selection error, register data are less valid than data generated by prospective randomized studies, so that conclusions from the observed phenomena must be evaluated with the necessary carefulness.

\section{Conclusions}

The current study provides evidence that restrictive blood transfusion and fluid management has become a common practice in severe injured children. A prehospital restrictive fluid management strategy in severely injured children is not associated with a worsened hemodynamic state, abnormal coagulation, or base excess but leads to higher hemoglobin levels. Further prospective studies are needed to investigate both transfusion and fluid concepts in paediatric trauma. The objective of such studies should be the implementation of treatment protocols for fluid and haemotherapy to provide recommendations based on a valid database.

Acknowledgements Open Access funding provided by Projekt DEAL.

Funding No funding has been received in connection to this study.

\section{Compliance with ethical standards}

Conflict of interest There are no conflicts of interest associated with this article.

Ethical approval The analysis was approved by the TR-DGU committee. The TR-DGU granted permission for publication.

Open Access This article is licensed under a Creative Commons Attribution 4.0 International License, which permits use, sharing, adaptation, distribution and reproduction in any medium or format, as long as you give appropriate credit to the original author(s) and the source, provide a link to the Creative Commons licence, and indicate if changes were made. The images or other third party material in this article are included in the article's Creative Commons licence, unless indicated otherwise in a credit line to the material. If material is not included in the article's Creative Commons licence and your intended use is not permitted by statutory regulation or exceeds the permitted use, you will need to obtain permission directly from the copyright holder. To view a copy of this licence, visit http://creativecommons.org/licenses/by/4.0/.

\section{References}

1. Nystrup KB, Stensballe J, Bottger M, Johansson PI, Ostrowski SR. Transfusion therapy in paediatric trauma patients: a review of the literature. Scand J Trauma Resusc Emerg Med. 2015;23:21. https ://doi.org/10.1186/s13049-015-0097-z.
2. Pickett PM, Tripi PA. Massive transfusion protocol in pediatric trauma. Int Anesthesiol Clin. 2011;49(2):62-7. https://doi. org/10.1097/AIA.0b013e3181f955d8.

3. Shroyer MC, Griffin RL, Mortellaro VE, Russell RT. Massive transfusion in pediatric trauma: analysis of the National Trauma Databank. J Surg Res. 2017;208:166-72. https://doi.org/10.1016/j. jss.2016.09.039.

4. Pieracci FM, Witt J, Moore EE, Burlew CC, Johnson J, Biffl WL, et al. Early death and late morbidity after blood transfusion of injured children: a pilot study. J Pediatr Surg. 2012;47(8):158791. https://doi.org/10.1016/j.jpedsurg.2012.02.011.

5. Maegele M, Lefering R, Paffrath T, Simanski C, Wutzler S, Bouillon B, et al. Changes in transfusion practice in multiple injury between 1993 and 2006: a retrospective analysis on 5389 patients from the German Trauma Registry. Transfus Med. 2009;19(3):117-24. https://doi.org/10.111 1/j.1365-3148.2009.00920.x.

6. Ruchholtz S, Nast-Kolb D, Waydhas C, Lefering R. The trauma register of the 'Polytrauma' Committee of the German Society of Trauma Surgery as the basis for quality management in the management of severely injured patients. Langenbecks Arch Chir Suppl Kongressbd. 1997;114:1265-7.

7. Narci A, Solak O, Turhan-Haktanir N, Aycicek A, Demir Y, Ela $\mathrm{Y}$, et al. The prognostic importance of trauma scoring systems in pediatric patients. Pediatr Surg Int. 2009;25(1):25-30. https ://doi.org/10.1007/s00383-008-2287-5.

8. Lefering R, Huber-Wagner S, Nienaber U, Maegele M, Bouillon B. Update of the trauma risk adjustment model of the TraumaRegister DGU: the Revised Injury Severity Classification, version II. Crit Care. 2014;18(5):476. https://doi.org/10.1186/ s13054-014-0476-2.

9. Goobie SM, Gallagher T, Gross I, Shander A. Society for the advancement of blood management administrative and clinical standards for patient blood management programs. Paediatr Anaesth. 2019;29(3):231-6. https://doi.org/10.1111/pan.13574 (4th edition (pediatric version)).

10. Karam O, Russell RT, Stricker P, Vogel AM, Bateman ST, Valentine SL, et al. Recommendations on RBC transfusion in critically III children with nonlife-threatening bleeding or hemorrhagic shock from the pediatric critical care transfusion and anemia expertise initiative. Pediatr Crit Care Med. 2018;19:S127-S132132. https://doi.org/10.1097/PCC.00000 00000001605.

11. Kozek-Langenecker SA, Ahmed AB, Afshari A, Albaladejo P, Aldecoa C, Barauskas G, et al. Management of severe perioperative bleeding: guidelines from the European Society of Anaesthesiology: first update 2016. Eur J Anaesthesiol. 2017;34(6):332-95. https://doi.org/10.1097/EJA.0000000000000630.

12. de Gast-Bakker DH, de Wilde RB, Hazekamp MG, Sojak V, Zwaginga JJ, Wolterbeek R, et al. Safety and effects of two red blood cell transfusion strategies in pediatric cardiac surgery patients: a randomized controlled trial. Intensive Care Med. 2013;39(11):2011-9. https://doi.org/10.1007/s00134-013-3085-7.

13. Tasker RC, Turgeon AF, Spinella PC, Pediatric Critical Care T, Anemia Expertise I, Pediatric Critical Care Blood Research N, et al. Recommendations on RBC transfusion in critically children with acute brain injury from the pediatric critical care transfusion and anemia expertise initiative. Pediatr Crit Care Med. 2018;19:S133-S136136. https://doi.org/10.1097/PCC.00000 00000001589 .

14. Steinbicker AU, Wittenmeier E, Goobie SM. Pediatric non-red cell blood product transfusion practices: what's the evidence to guide transfusion of the 'yellow' blood products? Curr Opin Anaesthesiol. 2020. https://doi.org/10.1097/ACO.0000000000000838.

15. Hwu RS, Spinella PC, Keller MS, Baker D, Wallendorf M, Leonard JC. The effect of massive transfusion protocol implementation 
on pediatric trauma care. Transfusion. 2016;56(11):2712-9. https ://doi.org/10.1111/trf.13781.

16. Kaufmann J, Laschat M, Wappler F. Medication errors in pediatric emergencies: a systematic analysis. Dtsch Arztebl Int. 2012;109(38):609-16. https://doi.org/10.3238/arztebl.2012.0609.

17. World Health Organization. Availability, safety and quality of blood products, vol. 63. World Health Assembly. 2010. https:// apps.who.int/iris/handle/10665/3086

18. Goodnough LT, Shander A. Patient blood management. Anesthesiology. 2012;116(6):1367-76. https://doi.org/10.1097/ ALN.0b013e318254d1a3.

19. Meybohm P, Herrmann E, Steinbicker AU, Wittmann M, Gruenewald M, Fischer D, et al. Patient blood management is associated with a substantial reduction of red blood cell utilization and safe for patient's outcome: a prospective, multicenter cohort study with a noninferiority design. Ann Surg. 2016;264(2):203-11. https://doi.org/10.1097/SLA.0000000000001747.

20. Lavoie J. Blood transfusion risks and alternative strategies in pediatric patients. Paediatr Anaesth. 2011;21(1):14-24. https://doi.org /10.1111/j.1460-9592.2010.03470.x.

21. Parker RI. Transfusion in critically ill children: indications, risks, and challenges. Crit Care Med. 2014;42(3):675-90. https://doi. org/10.1097/CCM.0000000000000176.

22. Istaphanous GK, Wheeler DS, Lisco SJ, Shander A. Red blood cell transfusion in critically ill children: a narrative review. Pediatr Crit Care Med. 2011;12(2):174-83. https://doi.org/10.1097/ PCC.0b013e3181e30d09.

23. Lacroix J, Hebert PC, Hutchison JS, Hume HA, Tucci M, Ducruet $\mathrm{T}$, et al. Transfusion strategies for patients in pediatric intensive care units. N Engl J Med. 2007;356(16):1609-19. https://doi. org/10.1056/NEJMoa066240.

24. Perez-Ferrer A, Gredilla-Diaz E, de Vicente-Sanchez J, Sanchez Perez-Grueso F, Gilsanz-Rodriguez F. Implementation of a patient blood management program in pediatric scoliosis surgery. Rev Esp Anestesiol Reanim. 2016;63(2):69-77. https://doi. org/10.1016/j.redar.2015.04.009.

25. Hussmann B, Lefering R, Kauther MD, Ruchholtz S, Moldzio $\mathrm{P}$, Lendemans $\mathrm{S}$, et al. Influence of prehospital volume replacement on outcome in polytraumatized children. Crit Care. 2012;16(5):R201. https://doi.org/10.1186/cc11809.
26. Hussmann B, Heuer M, Lefering R, Touma A, Schoeneberg C, Keitel J, et al. Prehospital volume therapy as an independent risk factor after trauma. Biomed Res Int. 2015;2015:354367. https:// doi.org/10.1155/2015/354367.

27. Al-Sharif A, Thakur V, Al-Farsi S, Singh RN, Kornecki A, Seabrook JA, et al. Resuscitation volume in paediatric non-haemorrhagic blunt trauma. Injury. 2012;43(12):2078-82. https://doi. org/10.1016/j.injury.2012.01.012.

28. Edwards MJ, Lustik M, Eichelberger MR, Elster E, Azarow $\mathrm{K}$, Coppola C. Blast injury in children: an analysis from Afghanistan and Iraq, 2002-2010. J Trauma Acute Care Surg. 2012;73(5):1278-83. https://doi.org/10.1097/TA.0b013e3182 $70 \mathrm{~d} 3 \mathrm{ee}$.

29. Maegele M, Lefering R, Yucel N, Tjardes T, Rixen D, Paffrath T, et al. Early coagulopathy in multiple injury: an analysis from the German Trauma Registry on 8724 patients. Injury. 2007;38(3):298-304. https://doi.org/10.1016/j.injury.2006.10.003.

30. Hendrickson JE, Shaz BH, Pereira G, Atkins E, Johnson KK, Bao $\mathrm{G}$, et al. Coagulopathy is prevalent and associated with adverse outcomes in transfused pediatric trauma patients. J Pediatr. 2012;160(2):204-9. https://doi.org/10.1016/j.jpeds.2011.08.019.

31. Whittaker B, Christiaans SC, Altice JL, Chen MK, Bartolucci AA, Morgan CJ, et al. Early coagulopathy is an independent predictor of mortality in children after severe trauma. Shock. 2013;39(5):421-6. https://doi.org/10.1097/SHK.0b013e3182 $8 \mathrm{e} 08 \mathrm{cb}$.

32. Oswald E, Stalzer B, Heitz E, Weiss M, Schmugge M, Strasak A, et al. Thromboelastometry (ROTEM) in children: age-related reference ranges and correlations with standard coagulation tests. Br J Anaesth. 2010;105(6):827-35. https://doi.org/10.1093/bja/ aeq258.

33. Vogel AM, Radwan ZA, Cox CS Jr, Cotton BA. Admission rapid thrombelastography delivers real-time "actionable" data in pediatric trauma. J Pediatr Surg. 2013;48(6):1371-6. https://doi. org/10.1016/j.jpedsurg.2013.03.036. 